\title{
SIMPLE PRETREATMENT METHOD DEVELOPMENT FOR IRON AND CALCIUM CARBONATE SAMPLES
}

\author{
Junghun Park ${ }^{1}$-Wan Hong • H J Woo • Han Woo Choi • Joonkon Kim • Gi Dong Kim \\ Korea Institute of Geoscience and Mineral Resources, 92 Gwahang-no, Yuseong-gu, Daejeon, 305-350, Korea.
}

\begin{abstract}
Since iron artifacts generally contain trace amounts of carbon, an iron sample needs to be relatively large, as compared to other materials, and a specially designed combustion system is required. An elemental analyzer (EA) was used for the combustion of iron without any special chemical treatment. $\mathrm{CO}_{2}$ gas with $1 \mathrm{mg}$ of carbon was obtained from the combustion of an iron artifact by using an EA and reduced to graphite for accelerator mass spectrometry (AMS) measurement. In this work, AMS dating results done at the Korea Institute of Geoscience and Mineral Resources (KIGAM) for several ancient iron artifacts are presented and compared with independently estimated ages. This method was found to be useful for the pretreatment of iron artifacts that contained $>0.1 \%$ carbon. A simple pretreatment method using an EA was also applied to calcium carbonate $\left(\mathrm{CaCO}_{3}\right)$ samples. Samples were preheated overnight at $100-300{ }^{\circ} \mathrm{C}$, without any special chemical treatment. This removed modern $\mathrm{CO}_{2}$ contamination and the background level decreased to a comparable value measured in samples treated with phosphoric acid under vacuum.
\end{abstract}

\section{INTRODUCTION}

The manufacture of iron involves the reduction of iron ore by smelting. During the smelting process, various materials are used as reducing agents, including charcoal, coal, and limestone. Throughout the early Iron Age in Korea, charcoal was mainly used for smelting. This charcoal provides a source for the carbon incorporated into the iron structure. If the charcoal used to smelt the iron ore was contemporaneous with the manufacture of the iron artifacts, then they can be dated by extracting the carbon from the iron artifact. Apart from exceptional cases in China, most smelting procedures in Asia were carried out by using charcoal until the Industrial Revolution. Moreover, many of the old iron artifacts were smelted from freshly cut wood. Therefore, within the error of accelerator mass spectrometry (AMS) analysis, the dates extracted from the carbon imply the date of manufacture (Cheoun et al. 2001; Kim et al. 2001).

Various methods for extracting carbon from iron artifacts have been introduced. The first method is the wet method, which involves dissolving the iron artifact samples with acid (Nakamura et al. 1995). Since the carbon is dissolved in the acid as a colloid because its size is too small to be extracted, it needs to be condensed for extraction. Fortunately, the carbon colloid is known to have a negative electrical property. Therefore, it can be precipitated with positive metallic ions. The second method is the simple wet method, which dissolving the iron samples with $2 \mathrm{M} \mathrm{HCl}$ at $85{ }^{\circ} \mathrm{C}$ (Scharf et al. 2004). In this method, the carbon colloid is separated from the solution, filtered with a glass filter, repeatedly washed with deionized water, and finally dried at $100{ }^{\circ} \mathrm{C}$. The third method is the dry method (van der Merwe and Stuiver 1968; Cresswell 1991, 1992). In this method, after being physically treated, iron samples are heated to the melting point in a furnace at which point carbon is released. The carbon from the iron samples is then oxidized to $\mathrm{CO}_{2}$ and trapped in a liquid nitrogen trap. In the fourth method, the iron artifact samples are chemically pretreated with $10 \%$ nitric acid, sealed under vacuum in quartz tubes in the presence of $\mathrm{CuO}$, and combusted at $1000{ }^{\circ} \mathrm{C}$ for a minimum of $10 \mathrm{hr}$ (Cook et al. 2001). The final method was developed in our laboratory and referred to here as the simple dry method. In this simple dry method, iron artifact samples are combusted in an elemental analyzer (EA) without special treatment. In the past, the EA generally has been used for the analysis of carbon, hydrogen, nitrogen, and sulfur after the samples have been

${ }^{1}$ Corresponding author. Email:junghun@kigam.re.kr.

(C) 2010 by the Arizona Board of Regents on behalf of the University of Arizona Proceedings of the 20th International Radiocarbon Conference, edited by A J T Jull RADIOCARBON, Vol 52, Nr 2-3, 2010, p 1295-1300 
combusted. For an exact analysis of $\mathrm{C}, \mathrm{H}, \mathrm{N}$, and $\mathrm{S}$, a complete combustion of samples are performed. Complete combustion can be performed efficiently for small samples in an EA.

Calcium carbonate $\left(\mathrm{CaCO}_{3}\right)$ can be converted to calcium oxide and carbon dioxide by means of calcination at temperatures $>900{ }^{\circ} \mathrm{C}$. Therefore, an EA can be used for this conversion (Yoneda et al. 2004). However, the background contamination level of the calcination method may be higher than that of the conventional method, which uses phosphoric acid under vacuum. In order to reduce background contamination, calcium carbonate samples were preheated overnight at various temperatures before the samples were calcinated with the EA.

\section{EXPERIMENTAL PROCEDURE}

Seven iron artifact samples were prepared (see Table 1). Sample TIr070001 was used for testing the combustion with the simple dry method. As can be seen in Figure 1, the cast iron was enveloped with thick rust, which was removed using a portable grinder. The cast iron was then cut into an appropriate size and polished with a sandblaster until the metallic color appeared. This step was followed by cleaning in deionized water in an ultrasonic bath for 3 min, after which the sample was dried. Finally, the cast iron was ground to a powder with a mortar and pestle (Figure 2). After physical treatment, the total organic carbon (TOC) of the iron powder was analyzed by using a small amount in the EA in order to check the carbon content of the sample. The measured TOC was used to estimate the weight of the iron artifact sample required to obtain 1 mg of carbon for AMS measurement. It was found that at least $16 \mathrm{mg}$ of iron artifact sample was necessary. Therefore, about $50 \mathrm{mg}$ of the iron artifact sample was used to attain an adequate amount of $\mathrm{CO}_{2}$.

Table 1 Iron samples used to test the simple dry sample processing method.

\begin{tabular}{|c|c|c|c|c|}
\hline Lab code & Sampling location & TOC & Estimated age & Calendar year $(1 \sigma)$ \\
\hline TIr070001 & $36^{\circ} 17^{\prime} \mathrm{N}, 126^{\circ} 52^{\prime} \mathrm{E}$ & $6.1 \%$ & AD 1st-7th century & $\begin{array}{l}\text { AD } 260(10.5 \%) 280 \\
\text { AD } 320(57.7 \%) 410\end{array}$ \\
\hline TIr070002 & & $3 \%$ & & $30,720 \pm 560 \mathrm{BP}$ \\
\hline TIr070003 & $38^{\circ} 37^{\prime} \mathrm{N}, 126^{\circ} 56^{\prime} \mathrm{E}$ & $3.9 \%$ & AD 15-19th century & AD $1420(68.2 \%) 1465$ \\
\hline TIr090001 & $\begin{array}{l}37^{\circ} 17^{\prime} 06.54^{\prime \prime} \mathrm{N}, \\
127^{\circ} 10^{\prime} 08.15^{\prime \prime} \mathrm{E}\end{array}$ & $\sim 4 \%$ & AD 11th century & $\begin{array}{l}\text { AD } 1050(9.7 \%) 1080 \\
\text { AD } 1150(58.5 \%) 1230\end{array}$ \\
\hline TIr090002 & $\begin{array}{l}37^{\circ} 17^{\prime} 06.54^{\prime \prime} \mathrm{N}, \\
127^{\circ} 10^{\prime} 08.15^{\prime \prime} \mathrm{E}\end{array}$ & $\sim 4 \%$ & AD 11th century & $\begin{array}{l}\text { AD } 1010(29.2 \%) 1050 \\
\text { AD } 1080(39.0 \%) 1160\end{array}$ \\
\hline TIr090003 & $\begin{array}{l}37^{\circ} 17^{\prime} 06.54^{\prime \prime} \mathrm{N}, \\
127^{\circ} 10^{\prime} 08.15^{\prime \prime} \mathrm{E}\end{array}$ & $3.9 \%$ & AD 11th century & AD 1180 (68.2\%) 1260 \\
\hline TIr090004 & $\begin{array}{l}37^{\circ} 17^{\prime} 06.54^{\prime \prime} \mathrm{N}, \\
127^{\circ} 10^{\prime} 08.15^{\prime \prime} \mathrm{E}\end{array}$ & $5.3 \%$ & AD 11th century & AD $1030(68.2 \%) 1160$ \\
\hline
\end{tabular}

Generally, the EA is equipped to handle samples of $\sim 1 \mathrm{mg}$. Larger samples reduce the combustion efficiency. Therefore, in order to enhance the combustion process in this case, the oxygen injection time of EA was increased from 12 to 20 s. Under these conditions, residual carbon disappeared in the EA spectrum after a second (empty) tin capsule was combusted following the iron sample. It was also confirmed that the TOC yield of the relatively large sample was comparable to small splits $(\sim 1 \mathrm{mg})$ of the same sample. The amount of $\mathrm{CO}_{2}$ gas obtained was $5.5 \mathrm{cc}$ at $1 \mathrm{~atm}$ for $50 \mathrm{mg}$ of iron.

An aliquot of the sample $\mathrm{CO}_{2}$ produced in the oxidation step was reduced using standard techniques to produce graphite (Vogel et al. 1987) (see Figure 4). Some $1.03 \mathrm{mg}$ of graphite was produced from $2.2 \mathrm{cc}, 1 \mathrm{~atm}$ of $\mathrm{CO}_{2}$, and the radiocarbon content of the sample was measured by AMS at the KIGAM facility (Figure 5). 


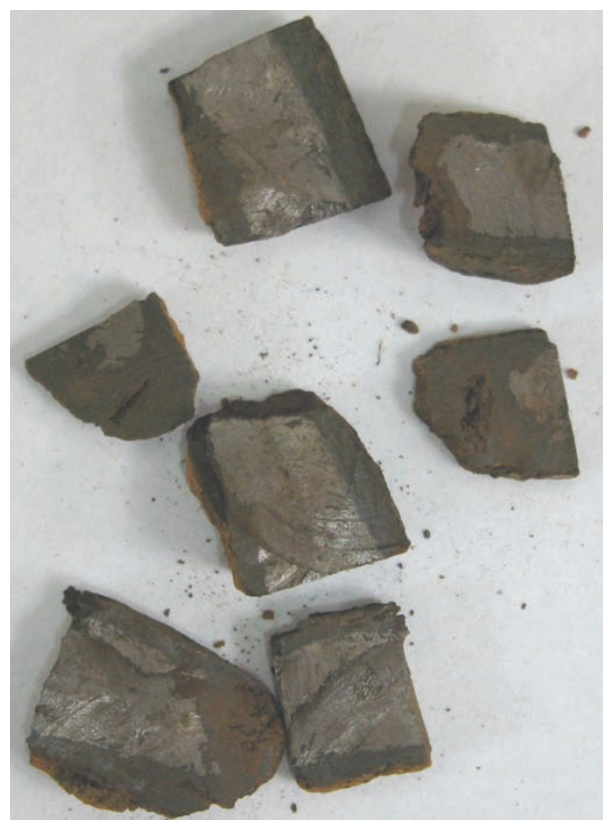

Figure 1 Photo of an iron artifact sample (TIr070001) with an estimated origin in the Three Kingdoms period (AD 1st-7th century).
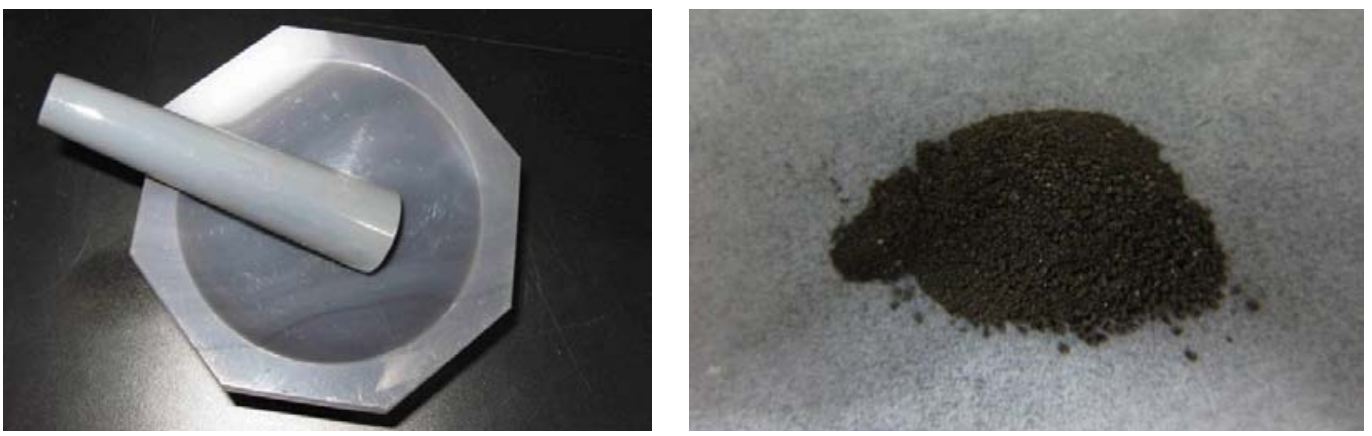

Figure 2 Photo of mortar and pestle (left) and iron powder produced after grinding the sample (right)

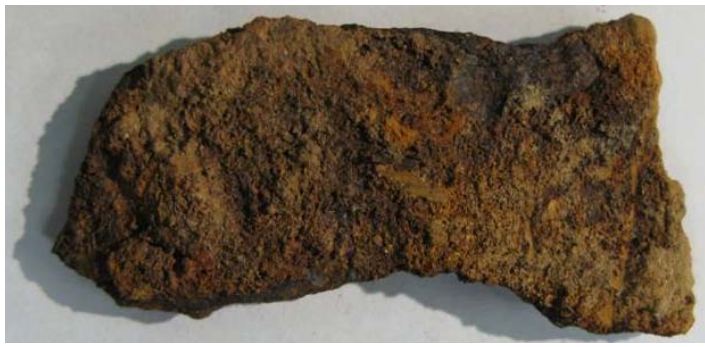

Figure 3 Photo of an iron artifact sample (TIr070002) estimated to be from the Choseon Dynasty (AD 15-19th century). 


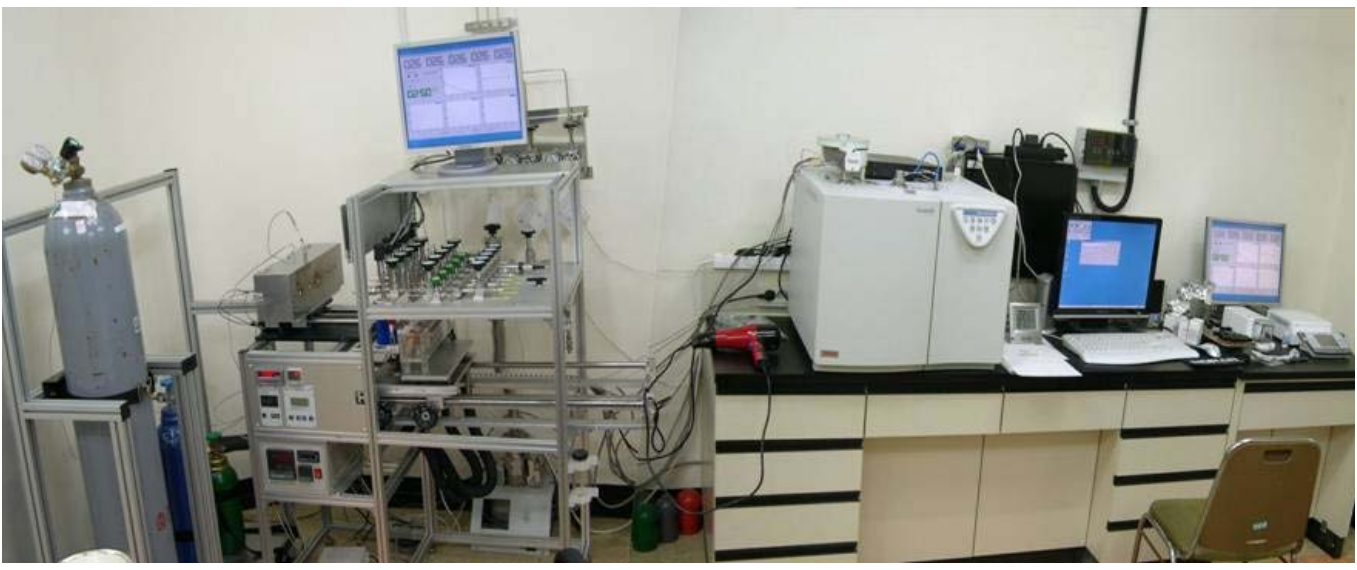

Figure 4 Photograph of the EA and reduction line

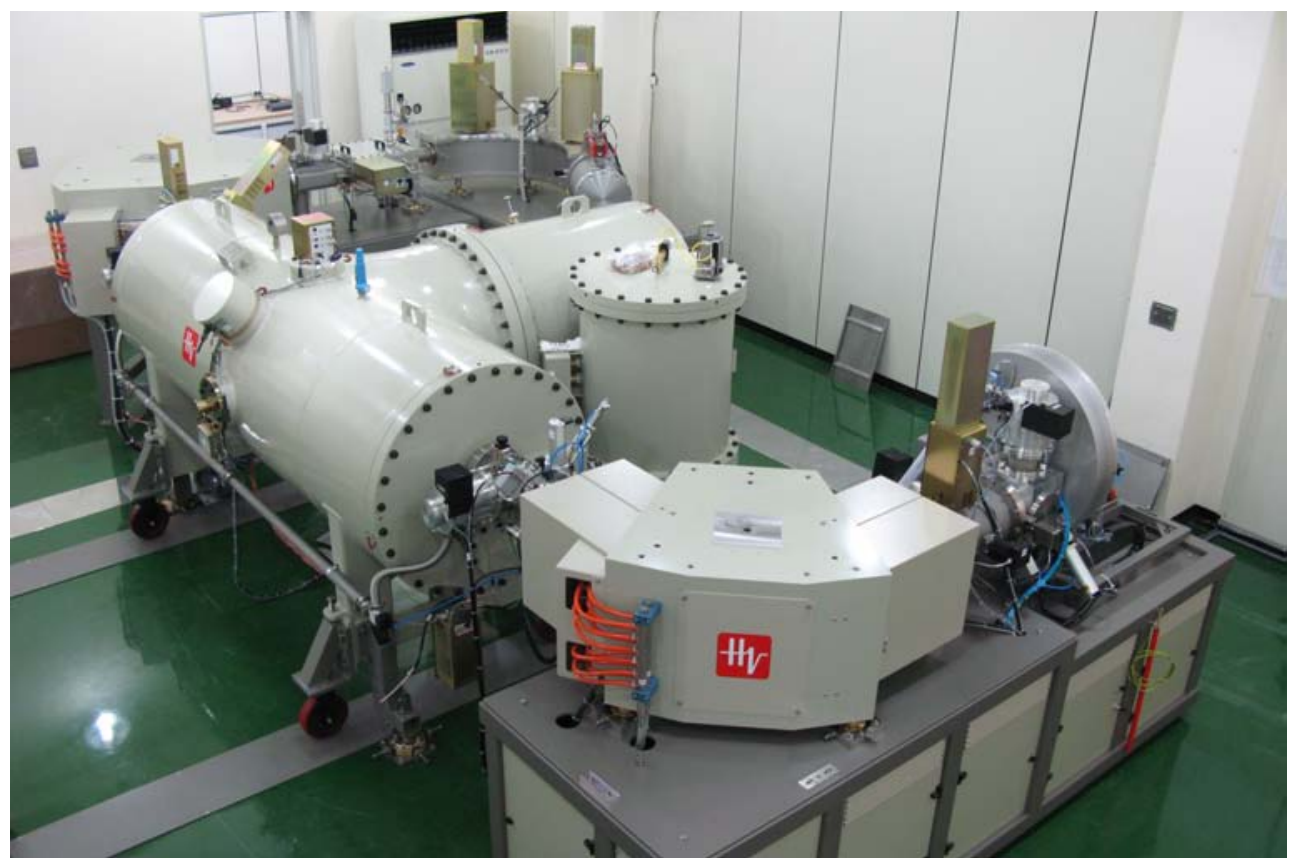

Figure 5 .Photograph of AMS at KIGAM (1 MV)

In the case of the TIr070002 sample (modern cast iron, Figure 3), $100 \mathrm{mg}$ of iron was treated using the same simple dry method with a strong oxidant $\left(\mathrm{V}_{2} \mathrm{O}_{5}\right)$ mixed with the sample in order to assist the combustion process and to eliminate residual $\mathrm{CO}_{2}$.

The calcination method used to process calcium carbonate samples is simple and direct, but the background contamination level was found to be high. To lower the background contamination level, calcium carbonate samples were calcinated after being preheated at $100{ }^{\circ} \mathrm{C}, 130{ }^{\circ} \mathrm{C}, 200{ }^{\circ} \mathrm{C}$, $250{ }^{\circ} \mathrm{C}$, and $300{ }^{\circ} \mathrm{C}$ overnight. In order to compare the results, some calcium carbonate samples were calcinated without preheating while others were treated in the conventional method by using 
phosphoric acid $\left(\mathrm{H}_{3} \mathrm{PO}_{4}\right)$ in a vacuum line. The $\mathrm{CO}_{2}$ gases produced were reduced to graphite and their ${ }^{14} \mathrm{C}$ content was measured by AMS.

\section{RESULT AND DISCUSSION}

Two sizes of tin capsules were used for the EA combustion process. Small tin capsules were used in most cases, whereas the large tin capsules were used for the combustion of samples with more than $\sim 100 \mathrm{mg}$ of iron. A large tin capsule can accommodate up to $500 \mathrm{mg}$ of iron artifact samples. In order to obtain $1 \mathrm{mg}$ of carbon, the carbon content of the iron artifact samples had to be at least $0.2 \%$. This procedure can be performed 2 or 3 times, but with careful attention to the state of the vacuum connection near the $\mathrm{LN}_{2}$ trap. Therefore, if the iron artifact sample contains between $0.1 \%$ and $0.2 \%$ carbon, the combustion of iron artifact samples can be performed using multiple EA steps. The lower limit in carbon content that can be treated by using the simple dry method is thus $\sim 0.1 \%$.

The measured ${ }^{14} \mathrm{C}$ ages of 7 iron artifact samples are shown in Table 1 . As expected, the modern cast iron sample shows a ${ }^{14} \mathrm{C}$ age of about 30,720 $\pm 560 \mathrm{BP}$. This result is expected on the assumption that coal was used in the smelting process. The ${ }^{14} \mathrm{C}$ ages of the 6 archaeological cast iron samples were found to be consistent with their estimated ages (Table 1).

Figure 6 shows the results for calcium carbonate samples that were preheated at various temperatures overnight. Preheating to above $200^{\circ} \mathrm{C}$ overnight lowered the background contamination levels of the calcium carbonate samples to below $0.1 \mathrm{pMC}$, similar to those of the conventional method that used phosphoric acid $\left(\mathrm{H}_{3} \mathrm{PO}_{4}\right)$ under vacuum. This suggests that preheating above $200{ }^{\circ} \mathrm{C}$ overnight or pumping in the vacuum line removes absorbed modern $\mathrm{CO}_{2}$ from the surface of the carbonate.

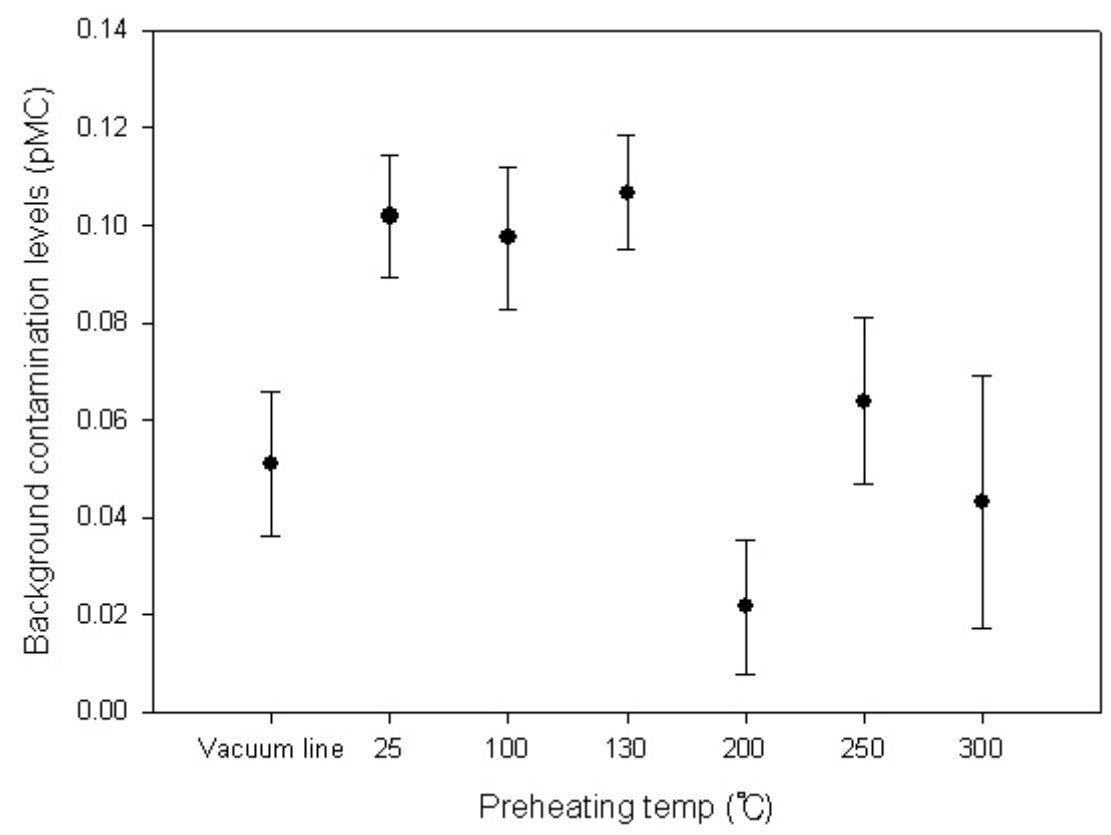

Figure 6 Relationship between preheating temperature of $\mathrm{CaCO}_{3}$ and background contamination levels in the calcination method and comparison of background contamination levels between the calcination method and conventional method that used phosphoric acid $\left(\mathrm{H}_{3} \mathrm{PO}_{4}\right)$ and a vacuum line. 


\section{CONCLUSION}

The simple dry method can be used for the pretreatment of most iron artifact samples, although this method may not be appropriate for samples that contain very small amounts of carbon $(<0.1 \%)$. The ${ }^{14} \mathrm{C}$ ages of the 7 iron artifacts were found to be in the range of their estimated ages. The results confirmed that neither contamination nor isotopic fractionation occurred during the procedure.

Calcination of calcium carbonate samples is a reliable and straightforward method for obtaining $\mathrm{CO}_{2}$. The high background contamination level can be solved by preheating the calcium carbonate samples above $200^{\circ} \mathrm{C}$ overnight. That is, the background contamination levels of calcium carbonate samples treated by the calcination method can achieve the same background levels obtained with the conventional method of phosphoric acid dissolution under vacuum.

\section{ACKNOWLEDGMENTS}

This work was supported by the General Research Project of Korea Institute of Geoscience and Mineral Resources (KIGAM) funded by the Ministry of Knowledge Economy.

\section{REFERENCES}

Cheoun MK, Kang J, Song YM, Kim JC, Kim IC, Park JH, Youn MY. 2001. Pretreatment of iron artifacts and bone at SNU-AMS. Journal of the Korean Physical Society 39(4):796-8.

Cook AC, Wadsworth J, Southon JR. 2001. AMS radiocarbon dating of ancient iron artifacts: a new carbon extraction method in use at LLNL. Radiocarbon 43(2A):221-7.

Cresswell RG. 1991. The radiocarbon dating of iron artifacts using accelerator mass spectrometry. Historical Metallurgy 25(2):76-85.

Cresswell RG. 1992. Radiocarbon dating of iron artifacts. Radiocarbon 34(3):898-905.

Kim JC, Park JH, Kim IC, Lee C, Cheoun MK, Kang J, Song YM, Jeong SC. 2001. Progress and protocol at the Seoul National University AMS Facility. Journal of the Korean Physical Society 39(4):778-82.

Yoneda M, Shibata Y, Tanaka A, Uehiro T, Morita M,
Uchida M, Kobayashi T, Kobayashi C, Suzuki R, Miyamoto K, Hancock B, Dibden C, Edmonds JS. 2004. AMS ${ }^{14} \mathrm{C}$ measurement and preparative techniques at NIES-TERRA. Nuclear Instruments and Methods in Physics Research B 223-224:116-23.

Nakamura T, Hirasawa M, Igaki K. 1995. AMS radiocarbon dating of ancient oriental iron artifacts at Nagoya University. Radiocarbon 37(2):629-36.

Scharf A, Kretschmer W, Morgenroth G, Uhl T, Kritzler K, Hunger K, Pernicka E. 2004. Radiocarbon dating of iron artifacts at the Erlangen AMS facility. Radiocarbon 46(1):175-80.

van der Merwe NJ, Stuiver M. 1968. Dating iron by the carbon-14 method. Current Anthropology 9(1):48-53. Vogel JS, Southon JR, Nelson DE. 1987. Catalyst and binder effects in the use of filamentous graphite for AMS. Nuclear Instruments and Methods in Physics Research B 29(1-2):50-6. 